\title{
Glândula mamária do mocó (Kerodon rupestris - Wied Neuwied, 1820): aspectos morfológicos
}

\author{
Marcelo Cardoso de LIMA $^{1}$ \\ Marina BONATELLI ${ }^{1}$ \\ Moacir Franco de OLIVEIRA² \\ Maria Angélica MIGLINO ${ }^{1}$ \\ Paulo Felipe Izique \\ $\mathrm{GOIOZO}^{3}$ \\ Simone Maria Massami \\ Kitamura MARTINS ${ }^{4}$ \\ Ana Flávia de CARVALHO
}

\begin{abstract}
Correspondência para:
Ana Flavia de Carvalho, Rua Alexandrino de Alencar no 242, 13860-000 Aguaí - SP, anaflaviac@uol.com.br, (19) 36343204/ 97662454
\end{abstract}

Recebido para publicação: 25/05/2006 Aprovado para publicação: 28/08/2008

\author{
1 - Departamento de Cirurgia da Faculdade de Medicina Veterinária e Zootecnia \\ da Universidade de São Paulo, São Paulo-SP \\ 2 - Centro de Multiplicação de Animais Silvestres da Escola Superior de \\ Agricultura de Mossoró, Mossoró-RN \\ 3 - Laboratório de Sanidade Animal do Centro Nacional de Pesquisa de Gado de \\ Corte, Empresa Brasileira de Pesquisa Agropecuária, Campo Grande- MS \\ 4 - Departamento de Nutrição e Produção Animal da Faculdade de Medicina \\ Veterinária e Zootecnia da Universidade de São Paulo, Pirassununga-SP \\ 5 - Departamento de Morfologia Animal da Faculdade de Medicina Veterinária da \\ Fundação de Ensino Octávio Bastos, São João da Boa Vista-SP
}

\section{Resumo}

Procurando colaborar com a exploração zootécnica racional dos mocós (Kerodon rupestris) foi descrita a morfologia da glândula mamária destes roedores, que por sua vez podem tornar-se uma fonte de alimento para população nordestina. Foram utilizados cinco animais cedidos pelo Centro de Multiplicação de Animais Silvestres (CEMAS) da pela Escola Superior de Agricultura de Mossoró (ESAM) registrado junto ao IBAMA como criadouro científico sob o número 12.492- 0004. As glândulas mamárias foram retiradas através de dissecação e foram fotografadas. Cada animal apresentou duas glândulas mamárias localizadas na região inguinal. Histologicamente a glândula mamária era composta por uma grande quantidade de lóbulos, repletos de glândulas túbulos-alveolares com epitélio simples cúbico. Na papila mamária fibras musculares apresentaram-se dispostas de modo circular, o que possivelmente auxilia na contração para excreção do leite.

\section{Introdução}

A problemática em torno da biodiversidade do planeta tem levado pesquisadores a desenvolver trabalhos no campo da ecologia animal, abordando aspectos de interesses ecológicos a fim de preservar àquelas espécies ameaçadas de extinção. Dentro deste contexto, os animais silvestres diferem daqueles domesticados pelo homem, que vem modificando de forma gradativa e progressiva o comportamento, a fisiologia, a anatomia e as características genéticas. A biologia comportamental, a fisiologia e a anatomia têm assumido papéis de elevada importância, uma vez que, propiciam formas de conhecimentos que permitem ao homem entender como interagem determinados grupos de animais em ambiente natural ou mesmo em regime de cativeiro.

Estes estudos muitas vezes levam em consideração caracteres reprodutivos, alimentares, ritmos biológicos, comportamento social, características fisiológicas e morfológicas que, na grande maioria das vezes, são realizados em função da importância ecológica que a espécie apresenta. Neste último caso enquadram-se os roedores, como as cutias, as capivaras, as pacas e em especial os mocós, dado aos maiores riscos de extinção que a espécie tem apresentado.

Os roedores são animais que oferecem extraordinária variedade de adaptações ecológicas, suportando os mais variados tipos de climas e altitudes, podendo manifestar diversas formas de adaptações 
fisiológicas. Apresentam tamanhos e formato de dentição características, por serem desprovidos de caninos e possuírem espaços entre incisivos e molares bem definidos. Podem, em função disto, apresentarem-se como arborícolas, rupícolas, terrícolas, mas com capacidade de acomodar-se parcialmente a mais de dois tipos de adaptações características. ${ }^{1}$

A família Caviidae abrange um grupo de roedores que se difere sob vários aspectos dos Hystrichomorpha, principalmente pela formação da mandíbula. A família Caviidae é pequena, constituída por animais pequenos e adaptada às condições de baixas altitudes. No Brasil é representada basicamente pelos gêneros Kerodon, Cavia e Gálea. ${ }^{2}$

Os mocós, Kerodon rupestris, são animais que apresentam uma mandíbula alongada, em que os dentes se distribuem de maneira especialmente particular quando comparados a outros tipos de roedores. ${ }^{1}$ Encontram-se distribuídos, no Brasil, em todos os Estados do Nordeste, especialmente na caatinga do semi-árido, e ao norte do Estado de Minas Gerais, sendo restritos a áreas rochosas, especialmente serrotes e serras, mas algumas vezes podem ser encontrados em lajeiros de planícies. ${ }^{3}$

Os mocós são poliéstricos e apresentam um ciclo reprodutivo relativamente longo, com maior período de gestação $^{4}$ (em média 75,9 dias ${ }^{5}$ ), menor tamanho de ninhadas (um a dois filhotes), menor tamanho ao nascer e menor relação peso ao nascer/peso da mãe. Apresentam ainda, idades ao atingir a maturidade sexual diferenciadas pelo sexo, variando em média em torno de 151 dias. $^{4}$ A gestação longa e a maturidade sexual-retardada podem ser possivelmente em virtude da especificidade de seu habitat. ${ }^{5}$

As glândulas mamárias de ratos foram caracterizadas como formações glandulares, tubulosas ou túbulo-ácinosas (dependendo do material estudado), embebidas em tecido conectivo frouxo e tecido adiposo da região abdominal e torácica. ${ }^{6}$ Observaram-se cinco pares de glândulas dispostas três na região torácica e duas na região abdome-inguinal.7 A posição das glândulas varia muito nas diferentes espécies, apresentam-se sempre aos pares e os ductos abrem-se em mamilos mais elevados. ${ }^{8}$ Cada lobo é de fato uma glândula mamária, com sua parte secretora e seu duto excretor próprio. Esses dutos excretores, chamados galactóforos, abrem-se independentemente na papila mamária ou mamilo. ${ }^{9}$

Durante a vida do animal, a glândula mamária sofre provavelmente maiores mudanças no tamanho, na estrutura, na composição e na atividade em relação a qualquer outro tecido. Essas mudanças começam durante a vida fetal e continuam até que a glândula atinja a maturidade, mediante ação de ondas hormonais durante os sucessivos ciclos reprodutivos. ${ }^{10}$

O tecido mamário continua a crescer após o parto e alcança o máximo crescimento durante o pico de lactação, sofrendo regressão após esse período. A quantidade de secreção de leite depende do crescimento do tecido epitelial túbuloalveolar da glândula mamária, processo que está sob controle hormonal. Com as gestações sucessivas, a glândula mamária vai aumentando seu desenvolvimento até atingir seu máximo potencial na terceira ou quarta gestação, cujas correspondentes lactações correspondem ao rendimento máximo. ${ }^{11}$

Diante da importância que o mocó poderá representar para as regiões mais carentes do país até como fonte de alimento, e considerando, a escassez de informações sobre a morfologia macro e microscópica reprodutiva dessa espécie, propomo-nos nesta oportunidade, descrever a morfologia da glândula mamária desses animais, procurando assim colaborar com futuras investigações, principalmente aquelas relativas à sua exploração zootécnica racional.

\section{Material e Método}

Foram utilizados cinco animais adultos cujas glândulas mamárias estavam em repouso, provenientes do Centro de Multiplicação de Animais Silvestres 
(CEMAS), criado pela Escola Superior de Agricultura de Mossoró (ESAM) registrado junto ao IBAMA como criadouro científico, localizado entre as coordenadas geográficas $5^{\circ} 11^{\prime} \mathrm{S}$ e $37^{\circ} 20^{\prime} \mathrm{W}$, com altitude ao redor de 16 metros.

Para a descrição da morfologia macroscópica, as glândulas mamárias foram fixadas pelo processo de perfusão, realizando injeção de solução aquosa de formol 10\%, posterior fixação por imersão. A seguir as glândulas mamárias foram dissecadas, fotografadas e as devidas posições in situ foram guardadas para posteriormente serem processadas e submetidas à técnica rotineira de inclusão em parafina (Histosec ${ }^{\circledR}$ ). As glândulas incluídas foram cortadas, em um micrótomo LEICA $^{\circledR}$ RM 2165, com espessura de $5 \mathrm{~mm}$ e foram coradas com hematoxilina-eosina, Tricrômio de Masson e Tricrômio de Gomory $^{12}$, submetidas a reações de ácido periódico de Shiff (P.A.S.) com fundo de hematoxilina de Harris ${ }^{13}$.

\section{Resultados}

Macroscopicamente, as fêmeas de mocó possuíam apenas duas glândulas mamárias que estavam situadas lateralmente ao plano mediano, na região abdominal caudal (inguinal). Cada glândula tinha o formato de um cone curto e achatado, dispostas perpendicularmente à linha mediana possuindo uma superfície medial plana. Eram constituídas por uma massa glandular ou corpo e papila ou teta. A base estava relacionada com a parede abdominal, encontrando-se aderida por tecido conjuntivo que continha inúmeros vasos e grande quantidade de gordura (Figura 1A). O pêlo da região ventral onde estavam inseridas as glândulas apresentou-se de cor clara diferindo da pele que cobre a glândula mamária que era pigmentada e fina (Figura 1B). A papila mamária ou teta, que também era achatada lateralmente apresentou variação no comprimento de dois a quatro milímetros. Ao redor de cada uma, existia uma região apresentando uma pequena quantidade de pêlos com diâmetro variando de quatro a cinco milímetros. No ápice de cada teta havia um orifício este denominado de abertura do ducto papilar ou óstio papilar (Figuras 1C e 2A). Microscopicamente, a glândula mamária apresentou-se dividida em lóbulos pelo tecido conjuntivo que carreava vasos e nervos para seu interior. Pode-se notar que os ductos secretores do interior do parênquima glandular cujo epitélio possuía áreas de epitélio pavimentoso e áreas de epitélio cúbico de acordo com sua tensão (Figura 2B). Na porção secretora da glândula pode-se evidenciar a formação túbulo-alveolar característica. Cada túbulo e alvéolo secretor possuíam um epitélio simples cúbico com células secretoras. Presença de grande quantidade de vacúolos nestas células indicou atividade secretora. Também observou-se a presença de grande quantidade de tecido adiposo unilocular ao redor dos alvéolos nas trabéculas de tecido conjuntivo (Figuras 2C, D e F). A papila mamária apresentou-se constituída histologicamente por um único ducto papilar, que conduzia o leite para fora da glândula através de um único óstio papilar (Figura 2A). As camadas histológicas constituintes da papila mamária do exterior até o interior do ducto papilar são: epitélio externo de revestimento era constituído pelo epitélio estratificado pavimentoso queratinizado, também chamado de epiderme com glândulas holócrinas ou sebáceas relacionadas aos folículos pilosos; lâmina própria, constituída de tecido conjuntivo frouxo (próximo ao epitélio, nas papilas dérmicas) e denso não modelado na derme; musculares, constituídas por duas camadas musculares lisas foram observadas circundando o ducto papilar (Figura 2A); lâmina própria do epitélio interno (ducto papilar) constituído por tecido conjuntivo frouxo denso não modelado e o epitélio de revestimento interno (ducto papilar) constituído por epitélio pavimentoso ou cúbico na luz do ducto papilar. 

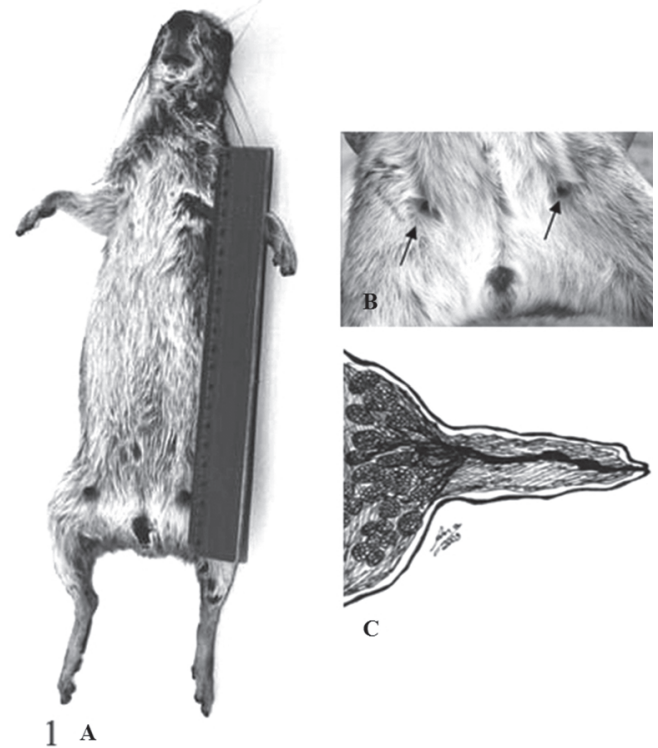

Figura 1 - A e B Fotografias, C esquema. Em A Kerodon rupestris e a posição in situ das duas glândulas mamárias do animal. B, detalhe da posição inguinal da glândula mamária e papilas mamárias. Em C, esquema mostrando a característica da arquitetura da glândula mamária e papila mamária em corte. Notar que os ductos glandulares se confluem para um único óstio papilar

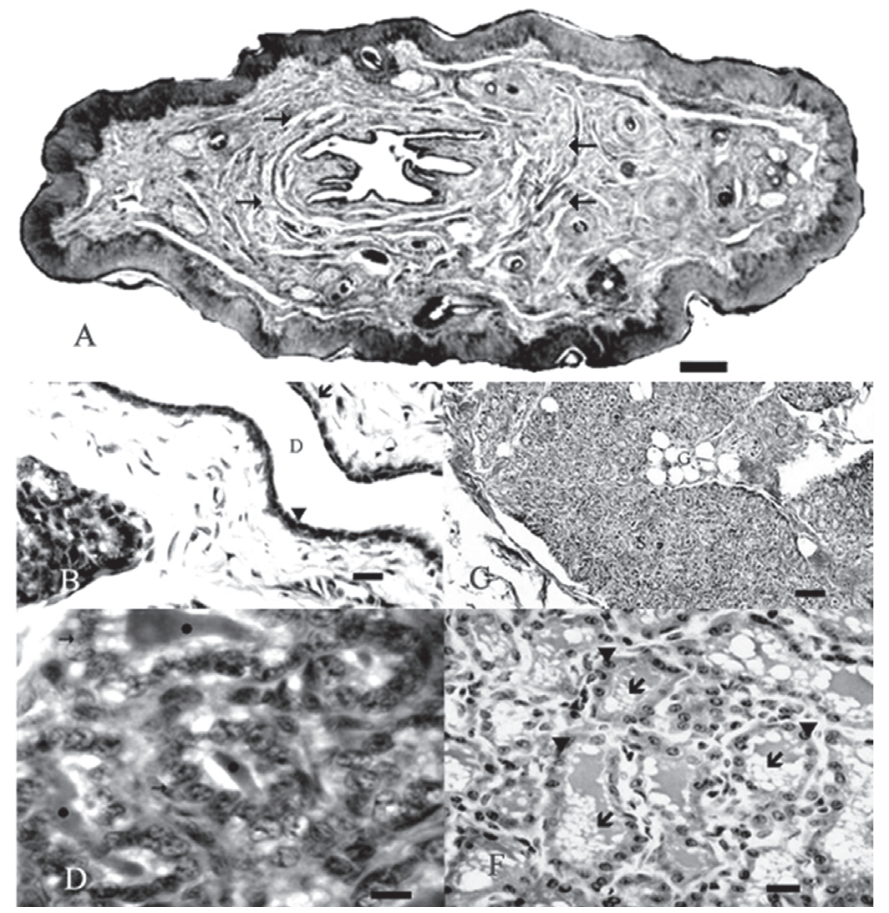

Figura 2 - Fotomicrografias. Em A, papila mamária do mocó em corte transversal pela coloração de Tricrômio de Masson. Notar a disposição das fibras musculares ('!) dispostas de modo circular ao ducto papilar (DP), Barra: 220mm. Em B, glândula mamária de mocó. Ductos secretores (D), observar o epitélio cúbico (cabeça de seta) que, em algumas porções, apresenta-se pavimentoso (í). H.E, Barra $20 \mathrm{~mm}$. Em C glândula mamária de mocó. Porção secretora (S), tecido conjuntivo $(C)$, tecido adiposo $(G)$. Tricrômio de Masson. Barra: 220mm. Em D glândulas túbulos-alveolares $(\bullet)$ contendo na luz, preenchimento de secreções PAS positivas (·). Reação PAS, Barra $11 \mathrm{~mm}$. F mostra a porção secretora, epitélio secretor (q), cujas células apresentam grande quantidade de vacúolos (í) indicando atividade glandular. Tricrômio de Gomory, Barra 20mm 


\section{Discussão}

Comparando-se com as glândulas mamárias dos animais domésticos ${ }^{14}$, o mocó não apresentou semelhança em relação ao formato e localização anatômica, porém, quanto comparado com o número de orifícios papilares (ductos papilares), apresentaram uma similaridade com as cabras e ovelhas. Os roedores apresentam uma grande quantidade de pares de glândulas mamárias dispostas em cristas mamárias podendo se estender da região inguinal até a região torácica. ${ }^{7,15}$

Os mocós possuíam um único par de glândulas mamárias, localizadas na região inguinal, diferente do comumente observado em animais domésticos e silvestres macroscopicamente. Microscopicamente tinham inúmeros lobos secretores, compostos por glândulas túbulos alveolares que confluíam um ducto excretor, assim como descrito em Guinea-pig (cobaia) ${ }^{8,16} \mathrm{em}$ animais silvestres e animais domésticos?.

Histologicamente a glândula lactífera é comprida e os lóbulos divididos por um conjunto tecidual de fibras musculares que são envoltos por uma cápsula e o leite é secretado por contrações das fibras musculares do mamilo. Na presente pesquisa, a glândula lactífera apresentou notadamente fibras musculares dispostas de modo circular à papila mamária, assim como no rato, o que pode auxiliar no processo de secreção do leite por contração da musculatura lisa, contudo não foram observadas células mioepiteliais na porção secretora glandular. ${ }^{17}$

Pode-se afirmar que a classificação adotada para as glândulas, de todas as espécies, são glândulas exócrinas túbulosalveolares, como evidenciado nas imagens de microscopia de luz feitas neste trabalho. Os ductos secretores das glândulas túbulosalveolares do Kerodon mpestris são diferentes em seu arranjo epitelial apresentando partes revestidas por epitélio pavimentoso e outras por epitélio cúbico diferindo do rato. ${ }^{6}$

\section{Conclusões}

O Kerodon rupestris possui um par de glândulas mamárias localizadas na região abdominal caudal pré-púbica (inguinal) que têm em cada uma, um único ducto papilar com apenas um óstio papilar. Histologicamente a glândula mamária é composta por uma grande quantidade de lóbulos, repletos de glândulas túbulosalveolares com epitélio simples cúbico preenchido de secreção. A papila mamária possui fibras musculares que estão dispostas de modo circular.

\section{Mammary gland of the rock cavy (Kerodon rupestris - Wied Neuwied, 1820): morphologic aspects}

\section{Abstract}

In attempt to collaborate with the rational zootecnic exploration of the Rock Cavy (Kerodon rupestris), the morphology of the mammary gland from these rodends was described, so that it can become a food source for northeastern population. Were used five animals yielded by the Center of Multiplication of Animals Savage (CEMAS), created by the Superior School of Agriculture of Mossoró (ESAM) registered in IBAMA as scientific breeding with number 12,492-0004. The mammary glands were remove through dissecation and were photographed. Each animal presented two mammary glands in the base of the insertion of the pelvic members in the abdominal region. Histologicaly the mammary gland is composed of a great amount of lobes, replete of alveolar tubs glands with cubical simple epithelium. Its mammary papilla showed an amount of muscular staple fibres in circular way that assists it in the contraction for excrement of milk.
Key words:

Rock Cavy.

Kerodon rupestris. Mammary gland. 


\section{Referências}

1 MOOJEN, J. Os roedores do Brasil. Rio de Janeiro: Instituto Nacional do Livro. Biblioteca Científica Brasileira, 1952. 214 p. (Série A-II)

2 ROOD, J. P. Ecological and behavioral comparisons of three genera Argentine cavies. Animal Behaviour Monographs, v. 5, p. 1-83, 1979.

3 STREILEIN, K. E. Ecology of small mammals in the seminarid brasilian caatinga. I. Climate and faunal composition. Annals of Carnegie Museum, v. 51, n. 5, p. 79-107, 1982.

4 KLEIMAN, D. G.; EISENBERG, J. F.; MALINIAK, E. Reproductive parameters and productivity of caviomorph rodents. In: KLEIMAN, D. G.; EISENBERG, J. F.; MALINIAK, E. Vertebrate ecology in the northern neo-tropics. Washington, DC: Smithhsonian Institution Press, 1979. p. 173-183.

5 ROBERTS, M.; MALINIAK, E.; DEAL, M. The reproductive biology of the rock cavy, Kerodon rupestris, in captivity: A study reproductive adaptation in a trophic specialist. Mammalia, v. 48, n. 2, p. 253 264, 1984.

6 JUNQUEIRA, L. C.; MARTINS, E. O. Atlas de anatomia microscópica do rato. São Paulo: Publicações da Universidade de São Paulo, 1947. p. 68.

7 LITTLE, C. C.; SNELL, G. D.; BITTNER, J. J.; CLOUDMAN, A. M.; PEKETE, E.; HESTON, W. E.; RUSSEL, W. I.; WOOLEY, G. W. Biology of the laboratory mouse by the staff of the Roscoe B. Jackson memorial laboratory. New York: Blakiston Company, 1941. p. $158-163$
8 ORR, R. T. Biologia dos vertebrados. 5. ed. São Paulo: Roca, 1986. 508 p.

9 JUNQUEIRA, L. C.; CARNEIRO, J. Histologia básica. 9. ed. Rio de Janeiro: Guanabara Koogan, 1999. $427 \mathrm{p}$.

10 KNIGHT, C. H.; PEAKER, M. Development of the mammary gland. Journal of Reproduction, v. 65, p. 522-536, 1982.

11 GONSÁLEZ, F. H. D. Introdução a endocrinologia reprodutiva veterinária. Porto Alegre: F.H.D. González, 2002.

12 BEHMER, O. A.; TOLOSA, E. M. C.; NETO, A. G. F. Manual de técnicas para histologia normal e patológica. São Paulo: Edart, 1976.

13 LILLIE, R. D.; FULMER, H. M. Histopathologic technic and practical histochemistry. 4. ed. New York: McGraw-Hill, 1976.

14 DYCE, K. M.; SACK, W. O.; WENSING, C. J. G. Tratado de anatomia veterinária. 2. ed. Rio de Janeiro: Guanabara Koogan, 1997. p. 147-155.

15 POPESKO, P.; RAJTOVA, V.; HORÁK, J. A colour atlas of anatomy of small laboratory animals. London: Wolfe, 1992. v. 2.

16 COOPER, G.; SCHILLER, A. L. Anatomy of the guinea-pig. Cambridge: Harvard University Press, 1975. p. 328-342.

17 KUBOTA, K.; SHIMIZU, Y.; SHIBANAI, S.; MAGAE, K.; NAGATA, S. Histological properties and biological significance of poch in red kangaroo. Macropus rufus. Anatomischer Anzuger, v. 168, p. 169-179, 1989. 